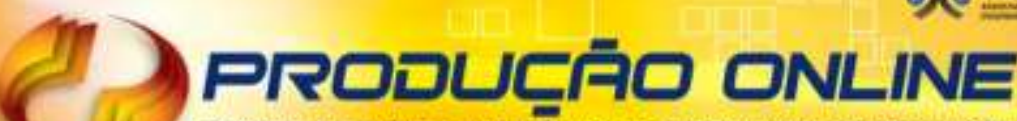 \\ REVISTA CIENTIFICA ELETRÖNICA DE ENGENHARIA DE PRODUÇAO \\ ISSN 1676-1901
}

\section{GESTÃO DA CADEIA DE SUPRIMENTOS VERDE: TENDÊNCIAS E DESAFIOS}

\section{GREEN SUPPLY CHAIN MANAGEMENT: TRENDS AND CHALLENGES}

\author{
Jairo José Assumpção* E-mail: jairo.assumpcao@posgrad.ufsc.br \\ Lucila Maria de Souza Campos* E-mail: lucila.campos@ufsc.br \\ *Universidade Federal de Santa Catarina (UFSC), Florianópolis, SC
}

\begin{abstract}
Resumo: Com o objetivo de resolver suas responsabilidades ambientais, as organizações estão cada vez mais concentrando-se em suas cadeias produtivas. Em função dessa característica, a Green Supply Chain Management (GSCM) tem recebido atenção crescente nos últimos anos. Assim, o objetivo deste artigo é apresentar uma visão abrangente e integrada da literatura publicada, a partir de 2006. Especial atenção foi dada para identificar os autores mais produtivos, evolução histórica do número de publicações e os periódicos que mais publicaram sobre a temática. A técnica utilizada foi a busca sistematizada, tendo como parâmetros os artigos publicados no sítio eletrônico Science Direct. Os principais resultados obtidos indicam que as publicações discutiram, em sua maioria, a importância da GSCM e operações verdes, evidenciando que reduzidas pesquisas abordam ecodesign. Em função da recorrência de novos temas, não abordados em revisões anteriores, evidenciou-se o desafio de se reestruturar as categorias propostas para análise do tema, contribuindo para o amadurecimento do campo.
\end{abstract}

Palavras-chave: Green Supply Chain Management. Práticas de GSCM. Revisão de Literatura.

\begin{abstract}
In order to solve their environmental responsibilities, organizations are increasingly concentrating on their productive chains. Given these characteristics, Green Supply Chain Management (GSCM) has received increasing attention in recent years. Thus, the objective of this article is to present a comprehensive and integrated view of the published literature, from 2006. Special attention was given to identify the most productive authors, historical evolution of the number of publications and the periodicals that published the most on the subject. The technique used was the systematized search, having as parameters the articles published on the electronic site Science Direct. The main results indicate that the publications discussed, for the most part, the importance of the GSCM and green operations, evidencing that fell researchers deal with ecodesign. Due to the recurrence of new themes not addressed in the previous review, the challenge was to restructure the proposed categories, contributing to the maturation of the field.
\end{abstract}

Keywords: Green Supply Chain Management. GSCM Practices. Literature review.

\section{INTRODUÇÃO}

Em função da aceleração de mudanças no cenário de produção global, potencializadas, principalmente, pelas novas tecnologias, as questões ambientais e sociais tornaram-se cada vez mais importantes na gestão de qualquer negócio. Assim, a maioria das empresas, com destaque para as que atuam na manufatura, 
estão buscando criar processos alinhados ambientalmente, a fim de atuarem num mercado cada vez mais competitivo e exigente em relação às questões ambientais.

Como essa inserção de questões ambientais na CS é um assunto recente é natural que ainda existam múltiplas formas de tratar o tema (JABBOUR et al., 2014; SRIVASTAVA, 2007). Por exemplo, Linton, Klassen e Jayaraman (2007) trataram GSCM como cadeias produtivas sustentáveis, Bai e Sarkis (2010) se referiram ao tema como gestão da cadeia ambientalmente sustentável e Zhu, Sarkis e Lai (2008) como gerenciamento de rede de fornecimento sustentável.

Em função dessa miríade de termos, existe uma crescente necessidade de pesquisas no âmbito da gestão de sistemas de produção, com o objetivo de consolidar conceitos, modelos e práticas ambientalmente amigáveis.

O campo interdisciplinar da GSCM tem crescido nos últimos anos, tanto no ambiente acadêmico como no ambiente industrial (JABBOUR et al., 2014; SARKIS, 2009). A preponderância de edições especiais dedicadas nos campos de operações e de gestão atestam essa tendência de passar a mirar em processos de eficiência ambiental e produção mais limpa (ZHU; SARKIS; LAI, 2008). Em função desse cenário, os principais temas chaves surgidos na literatura nas últimas duas décadas foram os conceitos de design verde, operações verdes, logística reversa, gestão de resíduos e de fabricação verde (GUIDE; SRIVASTAVA, 2007).

Nesse sentido, as preocupações ambientais e a inclusão de práticas verdes dentro da CS são assuntos que se tornaram relevantes na literatura atual. Esse fato ocorre em virtude do crescente interesse sobre a inclusão de processos que possibilitem minimizar os impactos ambientais das operações em todos os elos da cadeia (TRITOS; KEAH-CHOON; DOTUN, 2013; BARBIERI et al., 2014).

Tais processos, materializados por meio de práticas realizadas no decorrer das etapas da cadeia, tornam-se essenciais para a análise da eficácia sob a ótica econômica e ambiental, tendo como consequência a identificação de quão robusta é uma CS em relação ao desempenho ambiental. Diversos estudos (ELTAYEB; ZAILANI; RAMAYAH, 2011; TESTA; IRALDO, 2010; HOLT, 2004; TRITOS; KEAHCHOON; DOTUN, 2013) têm se preocupado na maioria dos casos em relacionar os processos de GSCM com o desempenho dos negócios, não se aprofundando em como tais mudanças alteram os processos de negócio e as estratégias funcionais. Outros estudos se preocuparam em relacionar as inovações da GSCM na ampliação 
de alternativas tecnológicas de reciclagem e reuso e na exigência de utilização de novos materiais (SELLITO et al., 2013).

Para tentar contribuir com esta discussão, Nadruz et al. (2017) elucidaram a relação entre práticas ambientais e desempenho financeiro no setor de construção e afirmaram que tal maturidade pode hierarquizar as empreiteiras quanto às práticas ambientais utilizadas. Portanto investimento em práticas ambientais podem melhorar o desempenho da organização por meio de alterações nos processos de negócios e nas estratégias funcionais. A formulação de estratégias verde pode incluir pesquisas sobre como as cadeias formulam objetivos e planos, alocar recursos na execução das atividades e agregam valor a clientes (SELLITO et al., 2013).

Tentando contribuir para diminuir essa lacuna Srivastava (2007) fez uma ampla revisão de literatura sobre o tema GSCM e dividiu o estado da arte, até aquele momento, em estudos que tratavam da importância da GSCM, operações verdes e ecodesign, o que chamou de contexto do problema. Seu objetivo geral era identificar uma direção para ajudar pesquisadores e profissionais na compreensão da integração da CS a partir da perspectiva ambiental. Passados onze anos e constatado que tal compreensão ainda não está amadurecida, surge a necessidade de complementar o estado da arte sobre essa temática a partir das pesquisas de Srivastava (2007). Portanto, o objetivo deste artigo é apresentar uma visão abrangente e integrada da literatura publicada a partir de 2006, identificando os principais autores, as preferências temáticas das pesquisas publicadas, os principais periódicos que publicam sobre o tema, apontando, com isso, os rumos para novos estudos.

Após essa introdução, o presente artigo descreve os procedimentos metodológicos utilizados. No item três faz um resgaste histórico das temáticas que foram abordadas nos diversos estudos publicados, a partir da revisão de Srivastava (2007), ressaltando a categorização proposta pelo autor. No item quatro, inicia com uma revisão bibliométrica dos trabalhos identificando os autores mais produtivos, a evolução histórica do número de publicações, as principais palavras chaves utilizadas e os periódicos que mais publicaram sobre a temática.

Após, amplia a revisão das publicações sobre o tema, a partir de 2006, buscando identificar a categorização no contexto do problema. No item cinco promove uma discussão a partir dos resultados, apontando possíveis rumos para 
novas pesquisas e encerra com as conclusões finais do estudo. A contribuição deste trabalho para a literatura está, justamente, em fornecer insights aos pesquisadores e praticantes de operações e da gestão da cadeia de suprimento, de como evoluiu o estado da arte da temática GSCM e quais as possíveis direções para futuras pesquisas.

O presente artigo está estruturado em mais três tópicos, além dessa introdução. O segundo tópico trata do estado da arte da GSCM, descrevendo também como a revisão sistemática foi realizada e as categorias utilizadas. $O$ terceiro tópico apresenta as discussões do artigo e o último item apresenta as principais conclusões da pesquisa.

\section{O ESTADO DA ARTE DA GSCM}

Este item iniciará com uma revisão sistemática sobre o tema GSCM a partir de 2006. Logo em seguida faz uma discussão a respeito do critério de Srivastava (2007) em tratar a temática da GSCM sob a ótica do contexto do problema. Finaliza o item revisitando a revisão realizada, sob esta ótica, com o objetivo de identificar a evolução do tema a partir de 2006. Encerra o item fazendo uma discussão sobre a temática propondo uma estrutura para organizar as publicações em GSCM.

\subsection{Revisão Sistemática}

A revisão sistemática (COOK; MULROW; HAYNES, 1997; COOPER, 1998; TRANFIELD; DEYER, 2003), do estado da arte sobre GSCM iniciou-se com a identificação e classificação dos principais trabalhos sobre o tema em questão, a partir de 2006 até o mês de dezembro de 2017. Após consolidadas as etapas de definição do problema e dos objetivos do estudo, passou-se à etapa de busca por fontes primárias de dados (KITCHENHAM, 2004), tendo como entrada a identificação dos artigos e periódicos disponíveis no sítio eletrônico Science Direct.

Foram utilizados como filtro título, resumo e palavras chaves para as duas expressões "GSCM ou Green Supply Chain Management. O critério utilizado retornou 577 artigos. Após as buscas, foi gerado um arquivo do tipo RIS (for EndNote, Reference Manager, ProCite) e exportado para execução no software 
EndNote. De posse desta base, passou-se à avaliação individual sobre a relevância dos mesmos para a área da gestão de operações. Foram eliminados aqueles que não se encaixavam nas premissas de pesquisa, por serem extremamente técnicos de áreas que não eram objeto deste estudo, (por exemplo, engenharia química, matemática, computação, entre outras áreas) restando na base 456 artigos. A tabela 1 apresenta os resultados finais dessa etapa da revisão.

Tabela 1 - Resultados após critérios de exclusão

\begin{tabular}{cc}
\hline Pesquisa & Artigos \\
\hline GSCM or "Green Supply Chain management" & 577 \\
Artigos excluídos & 121 \\
Total de artigos revisados & 456 \\
\hline
\end{tabular}

Fonte: Elaborado pelos autores (2018)

A segunda etapa iniciou-se com a criação de uma pasta no Excel e a inserção de diversas abas para alocação das informações. Após a identificação dos autores mais produtivos, da evolução histórica do número de publicações e os periódicos que mais publicaram, passou-se a leitura e organização dos títulos, palavra-chave, resumo e introdução para conhecer as preferências temáticas adotadas, com o objetivo de identificar o tipo de abordagem conforme níveis 1 e 2 , da figura 1, a seguir.

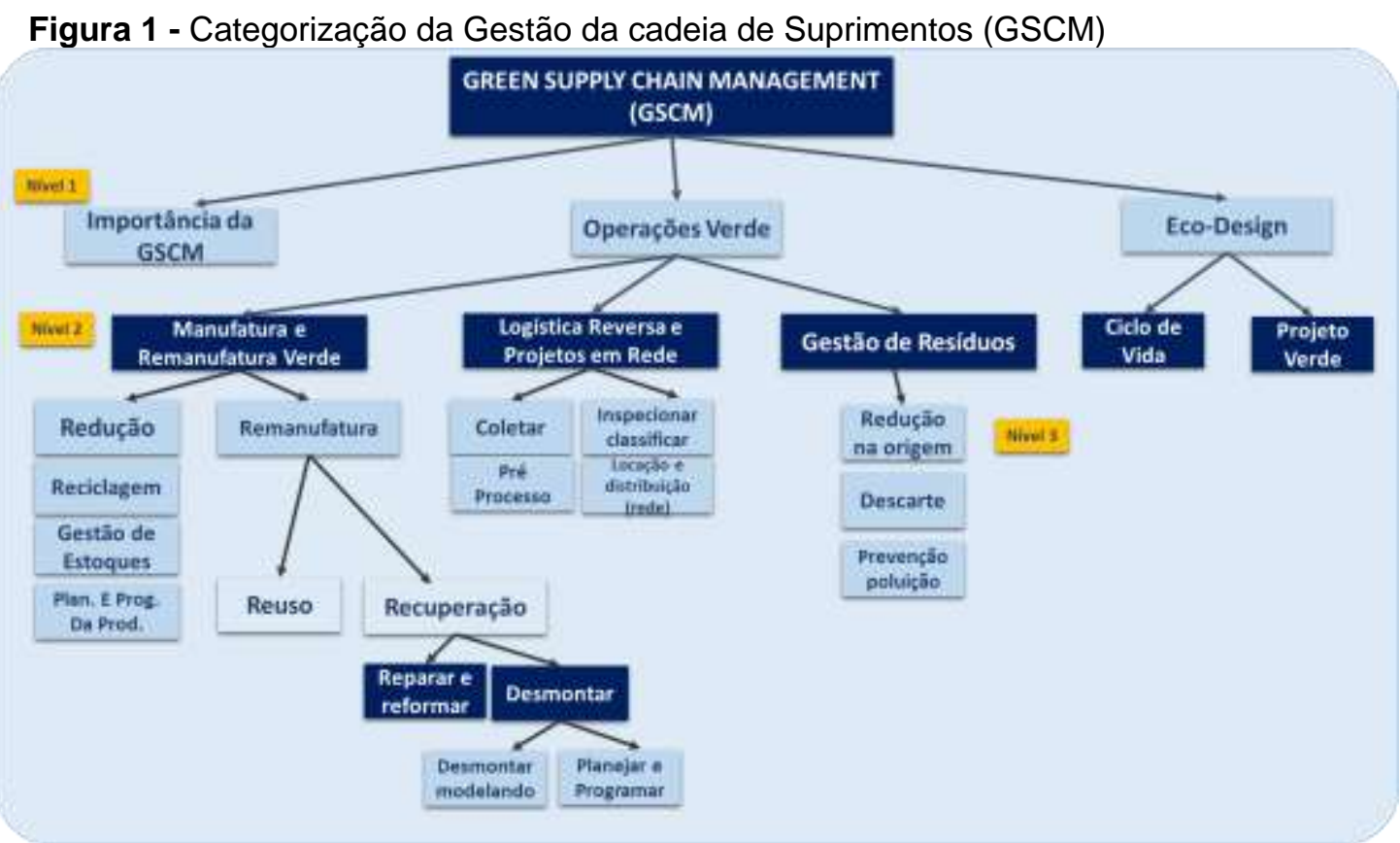

Fonte: Srivastava (2007) 
A partir dessa organização, foi feita uma análise dos artigos para identificar os principais direcionamentos de pesquisas em GSCM. Nesse caso, utilizou-se como base a classificação propostas por Srivastava (2007), níveis 1 e 2 da figura 1, desdobrando tais objetos de pesquisa em diversas categorias. A terceira etapa iniciou-se com a leitura completa de artigos selecionados em função da relevância, da temática alinhada às categorias propostas e à recorrência de publicações dos autores. O principal objetivo foi ampliar a visão dos pesquisadores acerca do tema para posterior inferências.

\subsection{GSCM - Abordagem contexto do problema}

Foi com a ótica da otimização dos processos aliada às preocupações ambientais que a GSCM passou a permear os estudos acadêmicos e profissionais, visando reduzir o desperdício e focar na qualidade do ciclo de vida do produto em relação aos recursos naturais. Ao se pesquisar na literatura sobre o tema em questão, verificou-se que as revisões encontradas têm um foco limitado e estreito sob tal perspectiva (HOLT; GHOBADIAN, 2009; ZHU; SARKIS, 2006), não cobrindo adequadamente todos os aspectos e facetas da GSCM.

A relevância em ampliar tais temáticas é potencializada ao se constatar que a GSCM é um assunto emergente que amplia em termos conceituais a perspectiva tradicional da gestão da CS. Enquanto o segundo conceito segue uma lógica de racionalização dos recursos da empresa durante essa cadeia, com o olhar para otimização dos processos e para o desempenho econômico, o primeiro insere a essa ótica critérios e/ou preocupações ambientais no ciclo de vida do produto ou serviço, bem como em decisões de compras organizacionais e suas relações de longo prazo com os fornecedores. Segundo Ganga et al. (2016) existe uma forte relação que comprova esta relação entre compras verde e a seleção de fornecedores, tanto nesta ordem como no sentido inverso.

Portanto, não é apenas a questão de tratar o meio ambiente de forma amigável e consciente, mas, sim, o bom senso de agregar valor ao negócio por meio de um direcionador de oportunidades.

O primeiro estudo sobre o tema foi publicado no final da década de oitenta e considerado uma publicação seminal. Nele, Kelle e Silver (1989) trataram 
especificamente sobre a logística reversa. O polêmico artigo tratava do desenvolvimento de um sistema de previsão ideal para que as organizações utilizassem a logística reversa, a fim de prever produtos que poderiam ser potencialmente reutilizados (FORTES, 2009). Com o passar dos anos, a academia mirou seus esforços em inserir a questão ambiental em todos os elos da CS, tendo como consequência um crescimento exponencial de estudos sobre a temática que hoje se conhece como GSCM.

Para ajudar na organização em relação à produção da área, Srivastava (2007) dividiu a produção científica em três grandes categorias de relevância: estudos que destacam a importância de GSCM, abordam operações verdes e tratam sobre ecodesign. Essa revisão focou as publicações anteriores a 2006.

$\mathrm{Na}$ primeira abordagem tratada por Srivastava (2007), além de considerar estudos de revisão de literatura, o trabalho identificou que os investimentos em greening poderiam gerar economia de recursos, eliminar o desperdício e, com isso, melhorar a produtividade. Nesse caso, destacam-se três abordagens: a ação empresarial é reativa, proativa ou para geração de valor (KOPICKI et al., 1993; VAN HOEK, 1999). A ação corretiva se preocupa com o cumprimento de requisitos legais, por meio de uma postura reativa baseada na percepção de incorrer em custos adicionais. Já na preventiva, o objetivo é a redução de custos e o aumento da produtividade em decorrência do uso eficiente dos recursos. Na dimensão de geração de valor, as empresas buscam integrar as atividades ambientais, como aquisição verde e implementação ISO 14.001, com iniciativas alinhadas às suas estratégias de negócios. A perspectiva muda então de greening como um fardo, para uma fonte potencial de vantagem competitiva (VAN HOEK, 1999).

Em relação a segunda abordagem - operações verdes - o principal foco está em descrever as práticas de GSCM. Os principais temas tratados pelas publicações passaram a caracterizar os desafios da GSCM, ao integrarem a remanufatura com operações internas (FERRER; WHYBARK, 2001), na compreensão dos efeitos da concorrência entre remanufatura e a integração do desenho de produto, bem como a integração da remanufatura com a logística reversa (CHOUINARD; D'AMOURS; AÏT-KADI, 2005; FLEISCHMANN et al., 2001).

Ainda, sobre operações verde, outros temas abordados foram: projetos para recuperação de materiais e produtos, economia de remanufatura, conservação e 
reciclagem, planejamento e controle da produção, fabricação verde, recuperação do produto e projetos de redes logísticas (GATENBY; FOO, 1990; MUKHOPADHYAY; SETOPUTRO, 2005; LENOX; KING; EHRENFELD, 2000).

A terceira abordagem - ecodesign - visa desenvolver uma compreensão de como as decisões de design afetam um produto em relação à sua compatibilidade ambiental (GLANTSCHNIG, 1994; NAVIN-CHANDRA, 1991) e, nesse caso, duas dimensões são priorizadas: análise do ciclo de vida e projetos verde. Assim, as questões que emergiram foram economia em remanufatura (AYRES; FERRER; LEYNSEELE, 1997) e conservação e reciclagem (GATEMBY; FOO, 1990), todos potencializados a partir da ótica do design produto.

A figura 1, apresentada anteriormente detalhou as três categorias discutidas, sob a ótica do contexto do problema, e faz menção aos dois níveis de análise abordados neste estudo para categorizar as temáticas, a partir de 2006. No nível 1, estão alocados os artigos, cujo objetivo proposto era tratar da temática sob a ótica da importância da GSCM, operações verdes, ou ecodesign.

Já no nível 2, a partir da categorização do nível 1, foram desdobrados os estudos que trataram de manufatura e remanufatura verde, logística reversa e projetos de rede, gestão de resíduos, ciclo de vida do produto e design verde.

\subsection{GSCM - Abordagem contexto do problema a partir de 2006}

Inicialmente, foi realizada uma análise sobre a recorrência de artigos publicados sobre o tema no período compreendido entre 2006 e 2017. Nesta linha histórica de publicações evidenciou-se um crescimento consistente de publicações sobre a temática, com exceção de declínios apresentado nos anos de 2009 e 2016. O ano com maior produção foi o de 2015 (72 publicações). Os resultados estão apresentados na figura 2 e consideram a base de publicações até a data de dezembro de 2017. 
Figura 2 - Número de publicações em periódicos sobre a temática

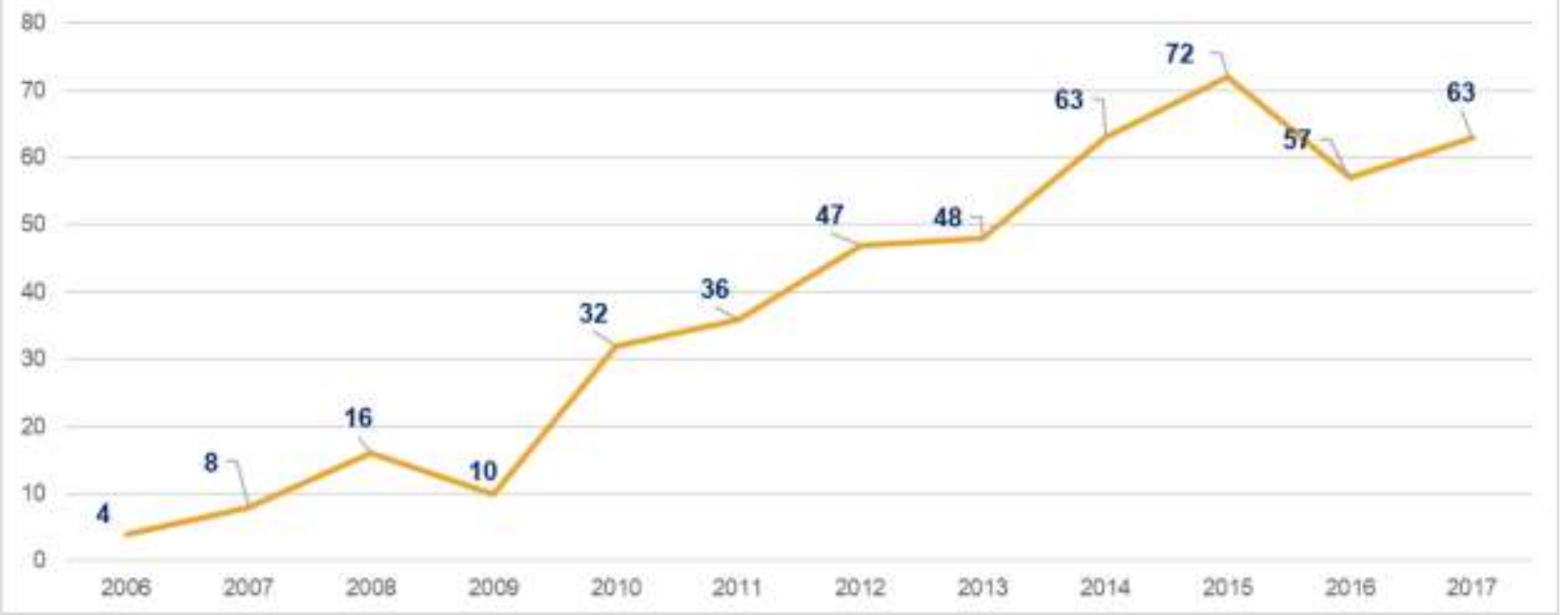

Fonte: Elaborado pelos autores (2018)

Em relação às principais revistas que publicaram sobre o tema destacam-se Journal of Cleaner Production com 36\% e International Journal of Production Economics com 16\%. Importante destacar que os primeiros 7 periódicos representam $80 \%$ das publicações sobre a temática GSCM. A figura 3, a seguir, apresenta os percentuais de publicações para as principais revistas.

Figura 3 - Percentual de publicações sobre GSCM por revistas no período de 2006 a 2017

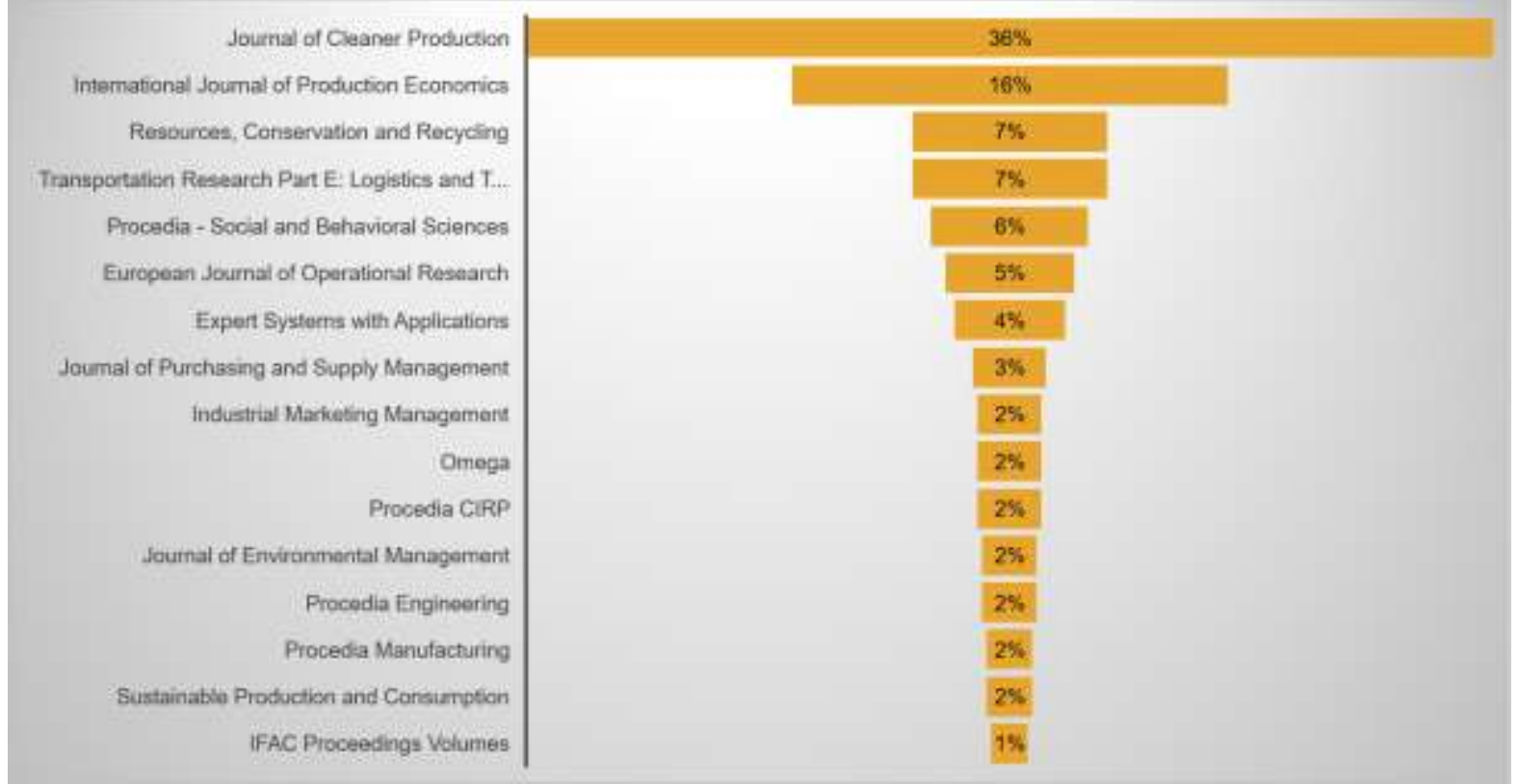

Fonte: Elaborado pelos autores (2018) 
Os principais autores que publicaram sobre a temática foram Joseph Sarkis, Charbel Jabbour e Geng Yong. Dos 456 artigos analisados, Joseph Sarkis participou, como autor, em 8,1\% das publicações pesquisadas. Já, Charbel Jabbour e Geng Yong, se destacaram também com 7,5\% e 6,8\% respectivamente.

A figura 4 faz uma ilustração sobre os principais autores que publicaram artigos sobre GSCM. Com o objetivo de identificar as principais palavras chaves utilizadas nos artigos avaliados, foram cadastradas, da exportação do sítio eletrônico, 2096 expressões utilizadas como palavras chaves. Deste total, 11\% das expressões mais utilizadas pelos autores foi Green Supply Chain Management ou Green Supply Chain que também aparece com a inserção da sigla GSCM.

Figura 4 - Quantidade de publicações por autores

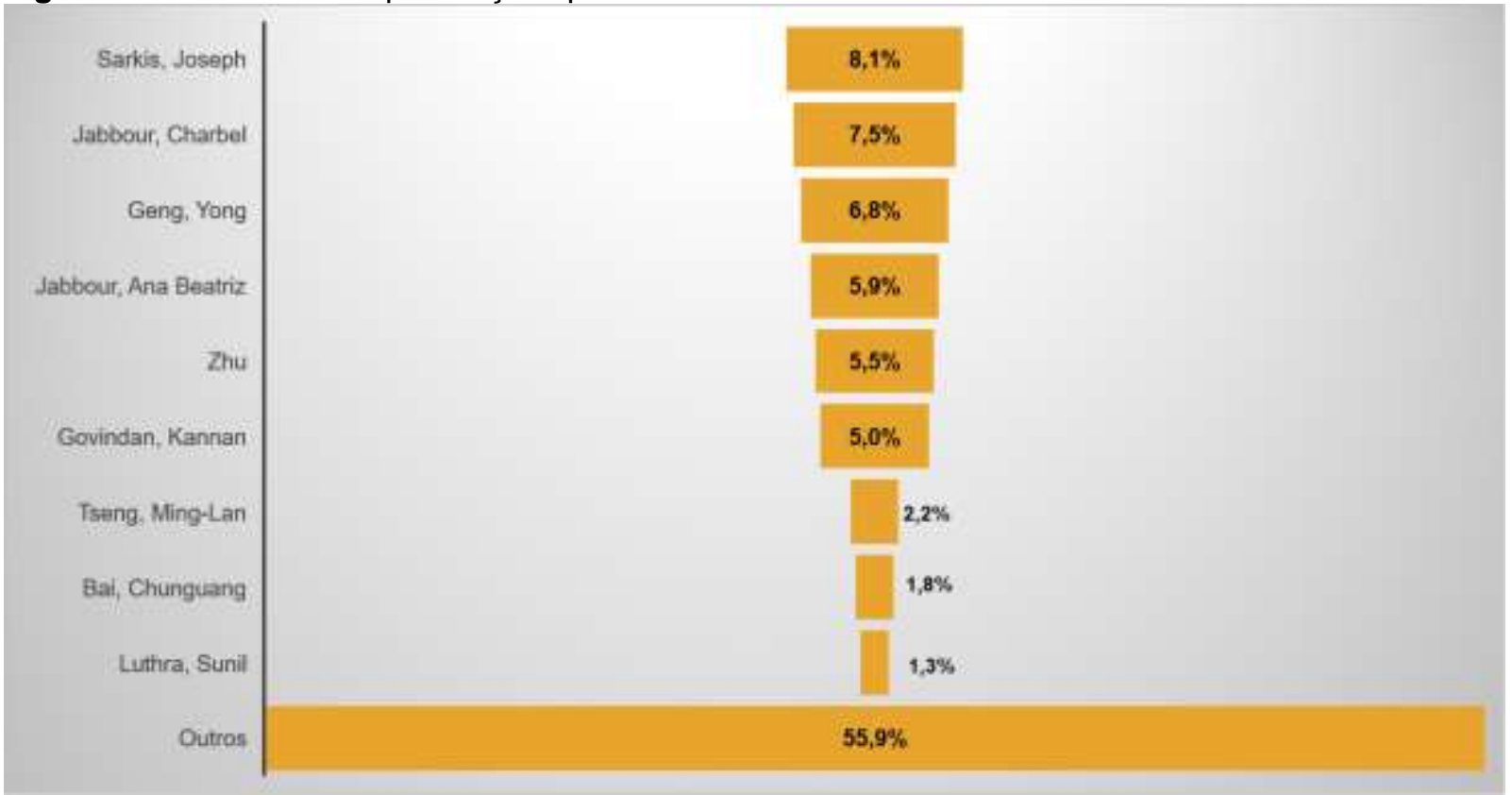

Fonte: Elaborado pelos autores (2018)

Outras expressões utilizadas e que merecem destaque em função do número de recorrência foram: Sustainability e Sustainable que aparecem ou sozinhas ou acompanhadas das expressões development, operations, manufacturing, production, practices entre outras e representam $6 \%$ das palavras indicadas e Supply Chain acompanhadas das expressões capabilities, management, integration, designs, performance entre outras com $5 \%$.

Em um número bem menor, também foram utilizadas expressões como fuzzy, environmental management, interpretive structural modeling (ISM), 
performance, DEMATEL, reverse logistics, green innovation, entre outras. A figura 5 faz uma representação da relevância de ocorrência das principais palavras chaves utilizadas.

Figura 5 - Relevância da recorrência das principais palavras chaves

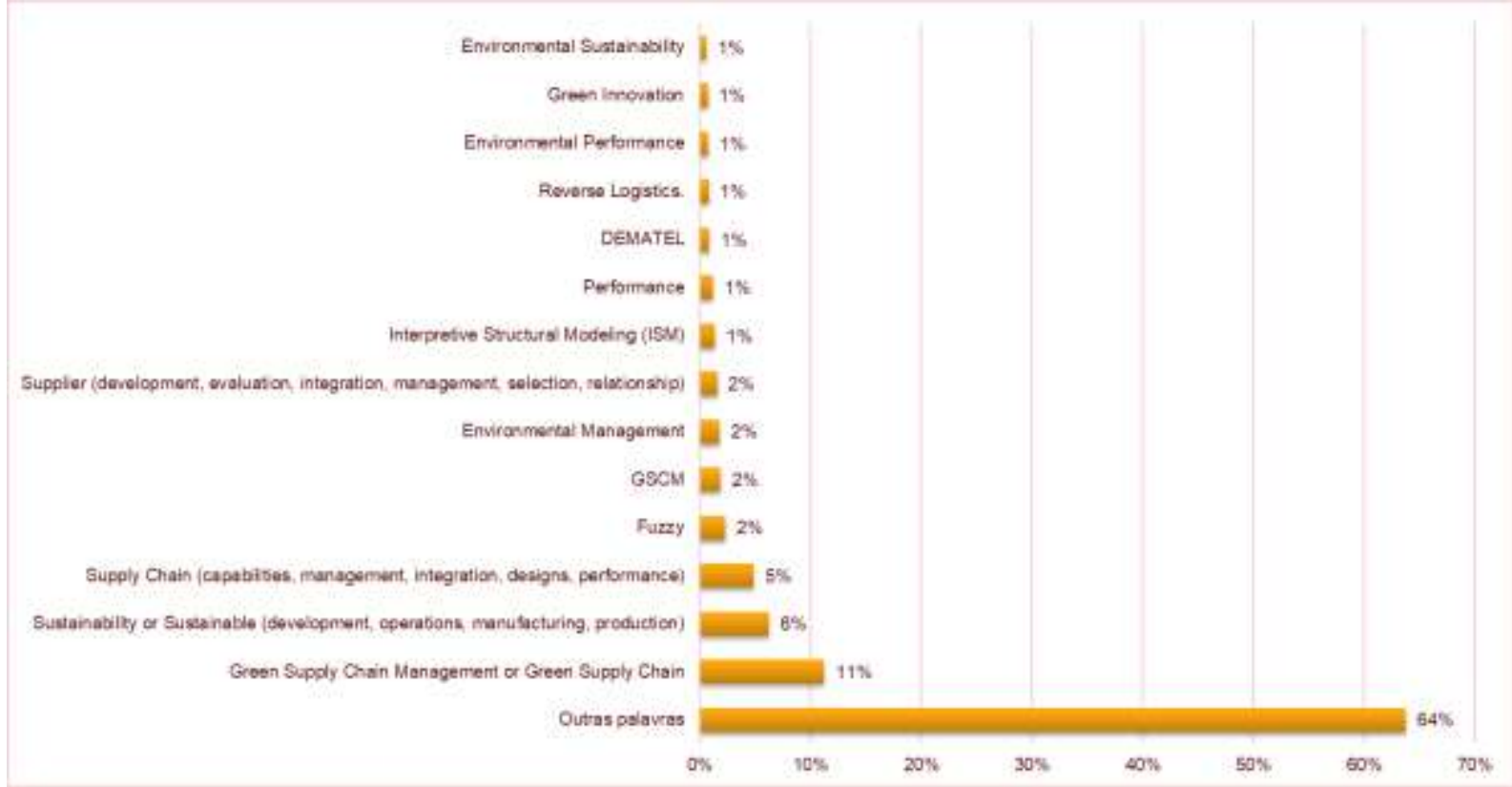

Fonte: Elaborado pelos autores (2018)

Ao se considerar o contexto do problema proposto por Srivastava (2007) que foi dividido em importância da GSCM, operações verdes e ecodesign pode-se identificar que as principais temáticas discutidas pelos autores foram a importância da GSCM, por meio de revisões de literatura e motivações e barreiras para a implantação da GSCM com 57,6\% das publicações. Em segundo lugar ficou a preferência por temáticas relacionadas a operações verdes com 36,7\%. Poucas publicações trataram do tema ecodesign representando apenas 5,7\%. A figura 6 demonstra esta relação entre as preferências temáticas dos autores pesquisados. 
Figura 6 - Temáticas preferenciais em relação ao contexto do problema

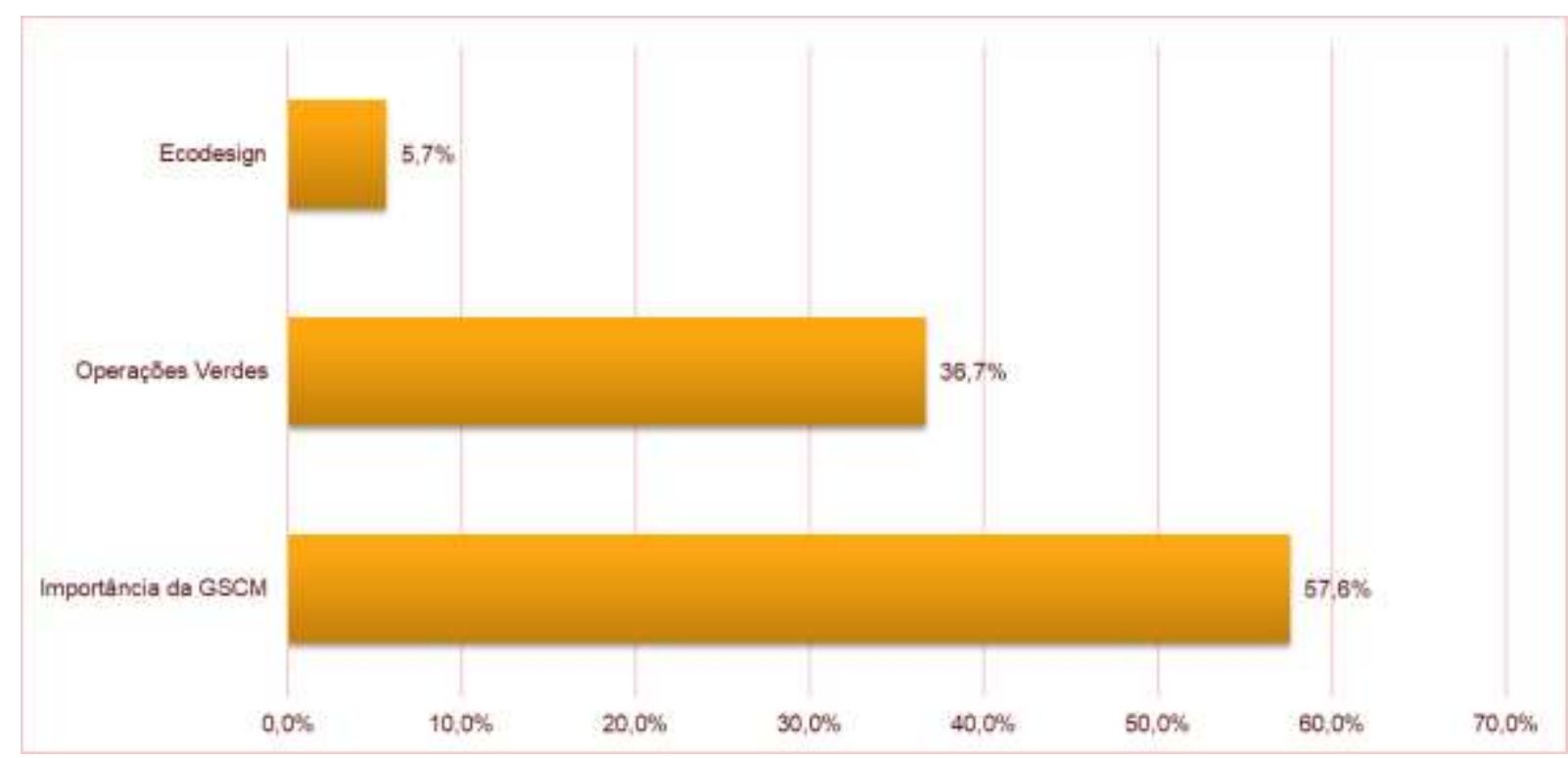

Fonte: Elaborado pelos autores (2018)

Em resumo, sobre a abordagem contexto do problema, os principais estudos publicados sobre GSCM indicam uma tendência de polarização para a escolha de temas sobre a importância da GSCM e sobre operações verdes (logística reversa, gestão de resíduos e de fabricação verde).

Em relação a importância da GSCM pode-se exemplificar a discussão sobre pressões ecológicas na China (ZHU; GENG; SARKIS, 2016), consciência regulatória em empresas chinesas e japonesas (ZHU et al., 2015), oportunidades da ecoeficiência baseada na gestão da cadeia de suprimentos verde (GOVINDAN et al., 2014), práticas e barreiras de implementação da GSCM e revisão teórica da literatura de GSCM (ZHU; SARKIS; LAI, 2012).

Importante destacar que as categorias propostas por Srivastava (2007) desdobraram-se em outras temáticas que foram abordadas nos estudos anteriores de forma incipiente demonstrando, com isso, uma ampla evolução da temática GSCM.

Assim os estudos publicados no período, passaram a tratar de forma mais recorrente de temas como por exemplo inovações ambientais (CHIOU et al., 2011; ELTAYEB; ZAILANI; RAMAYAH, 2011; YARAHMADI; HIGGINS; CLEMENTS, 2012), cooperação com fornecedores (JABBOUR; JABBOUR, 2009; ZHU; SARKIS; LAI, 2012; SINGHAL, 2013); cooperação com clientes (ZHU; GENG; SARKIS, 2016; GOVINDAN; JABBOUR; JABBOUR, 2014; MAHMOOD et al., 2013); green 
marketing (GOVINDAN; JABBOUR; JABBOUR, 2014; HSU et al., 2013, SHANG; LU, LI, 2010) e requisitos legais (ELLRAM et al., 2008; GOVINDAN; JABBOUR; JABBOUR, 2014; ELTAYEB; ZAILANI; RAMAYAH, 2011; HOLT; GHOBADIAN, 2009).

Analisando sob a ótica das operações verdes pôde-se identificar que a estruturação não se alterou significativamente e a principal temática escolhida pelos autores foi manufatura e remanufatura com $40 \%$ dos trabalhos publicados. O quadro 2 apresenta uma estrutura ampliando as temáticas tratadas na categoria importância da GSCM.

Quadro 2 - Importância da GSCM - temáticas ampliadas

\begin{tabular}{|c|c|}
\hline INOVAÇOES AMBIENTAIS & Autories: \\
\hline Funçôes de inovação e maior investimentos em P\&D & \multirow{2}{*}{ Tseng et al. (2013) } \\
\hline Grau de inovação da P\&D em produtos verdes & \\
\hline Uso de fontes alternativas de energia & Wan Mahmood et al. (2013) \\
\hline Programas de incentivo aos empregados para sugestões ambientais & Vachon \& Klassen (2006) \\
\hline Mudar tecnologias sujas para tecnologias mais limpas & Vachon (2007) \\
\hline COOPERACGAO COM FORNECEDORES & Autores: \\
\hline Certificação de fornecedores e certificação ISO 14001 dos fornecedores & $\begin{array}{l}\text { Zhu, Sarkis \& Lai, (2012) Thun, } \\
\text { Muller (2010) }\end{array}$ \\
\hline $\begin{array}{l}\text { Cooperando com os fornecedores para lidar com as questôes ambientais de } \\
\text { consumo de end-of-pipe }\end{array}$ & Singhal (2013) \\
\hline Critérios de seleção de fornecedores verdes & Jabbour \& Jabbour (2009) \\
\hline COOPERACAOO COM CLIENTES & Autores \\
\hline Cooperaçåo com os clientes para uma produçåo mais limpa, & \multirow{3}{*}{ Zhu, Geng \& Sarkis (2016) } \\
\hline Cooperação com os clientes para a embalagem verde, & \\
\hline Cooperação com os clientes para logistica reversa & \\
\hline Trabalhar com os clientes para ecodesign & \multirow{2}{*}{$\begin{array}{l}\text { Govindan, Jabbour \& Jabbour } \\
\qquad(2014)\end{array}$} \\
\hline Trabalhar com os clientes para tornar a produção mais limpa & \\
\hline $\begin{array}{l}\text { Fornecer aos consumidores informaçōes sobre os produtos ecológicos e/ou } \\
\text { métodos de produção }\end{array}$ & Mahmood et al. (2013) \\
\hline MARKETING VERDE & Autores \\
\hline Marketing verde & Shang, Lu \& Li (2010) \\
\hline Educaçẫo $\mathrm{e}$ formação ambiental & Hsu \& Hu (2010) \\
\hline Trabalho de mão de obra para práticas verdes & \multirow{2}{*}{ Govidan, Jabbour \& Jabbour(2014) } \\
\hline Envolvimento organizacional orientada para práticas verdes & \\
\hline Gerenciamento de imagem verde & Shang,Lu \& Li (2010) \\
\hline REQUISITOS LEGAIS & Autores \\
\hline Gestāo ambiental e legislativa & Eltayeb, Zailani \& Ramayah (2011) \\
\hline $\begin{array}{l}\text { Conformidade com legislação ambiental vigente da UE e eventual legislação } \\
\text { ambiental no futuro }\end{array}$ & Holt \& Ghobadian (2009) \\
\hline Apoio da alta gestão e dos gestores intermediários para GSCM & Ellram, et al. (2008) \\
\hline Compromisso de gerẻncia sẻnior para GSCM & Govindan, Jabbour \& Jabbour (2014) \\
\hline
\end{tabular}

Fonte: Elaborado pelos autores (2018) 
Logística reversa e projetos de rede e gestão de resíduos foram discutidos em $13 \%$, dos trabalhos pesquisados. Um ponto a se destacar é que houve uma preferência bastante relevante dos autores em discutir práticas de GSCM de forma integrada. Por exemplo ao se investigar as práticas de lean e green no gerenciamento de cadeia de suprimentos verdes para melhorar sua ecoeficiência (CARVALHO et al., 2017) e a integração de lean manufacturing focado em técnicas de redução de resíduos nos processos de fabricação (FAHIMNIA; SARKIS; ESHRAGH, 2015). Esta nova estrutura de investigação de práticas integradas correspondeu a $40 \%$ dos trabalhos avaliados.

Uma outra temática que permeou os trabalhos foi a de tecnologia da informação. Apesar de ser ainda insipiente, correspondendo a $4 \%$ dos estudos pesquisados, esta evidência demonstra uma preocupação com a integração de sistemas de informação como suporte a decisões na CS. Por exemplo a discussão sobre infraestrutura de $\mathrm{Tl}$ e agressividade competitiva para previsão do desempenho (AJAMIEH et al., 2016), a adoção de práticas de gerenciamento da GSCM que incluem sistemas de tecnologia da informação verde (GITS) para ajudar a fornecer benefícios econômicos na gestão com os fornecedores e outras práticas (BAl; KUSISARPONG; SARKIS, 2017) e como a implantação Warehouse Management System (WMS) na logística reversa, pode contribuir para a gestão eficiente e a redução de custos (FIGUEIRA; BURI, 2017).

Finalmente, sobre a categoria ecodesign, os estudos centraram-se em ciclo de vida do produto (48\%) e design verde (52\%). Com relação ao ciclo de vida do produto, Bojarski et al. (2009), analisaram os impactos e regulamentos ambientais para modelagem de cadeias de suprimentos e Mehmet (2013) analisaram a GSCM sob a ótica da vida útil do produto. Em relação a projetos verdes, Wang, Lai e Shi (2011) analisaram a otimização multi objetivo para o projeto verde de rede da CS como sistemas de apoio à decisão e Tseng et al. (2013) investigaram o consumo e a produção sustentáveis na Ásia, analisando a sustentabilidade por meio das práticas de design verde.

\section{DISCUSSÕES}

A partir de uma perspectiva do estudo realizado, constata-se a necessidade Revista Produção Online. Florianópolis, SC, v. 18, n. 4, p. 1470-1494, 2018. 
de uma compreensão melhor da categorização proposta por Srivastava (2007), além de uma análise mais aprofundada sobre qual rumo está sendo condutor dos estudos recentes sobre GSCM. Nesse sentido, algumas questões se colocam: o campo GSCM está consolidado, e os esforços devem ser direcionados para pesquisas em operações verdes e ecodesign? Como integrar um modelo de planejamento estratégico de GSCM com os modelos operacionais e com isso gerar vantagem competitiva por meio da inovação em práticas ambientais? (CHIOU et al., 2011, VACHON; KLASSEN, 2008; SARKIS et al., 2011); como estabelecer incentivos para a condução da sustentabilidade e como evolui as práticas de GSCM sob a ótica de inovações ambientais? (BAI; SARKIS; WEI, 2012); como lidar com as barreiras e potencializar motivações para a implementação da GSCM? Como as práticas de GSCM potencializam a consolidação de um sistema de gestão ambiental?

Tais questões são decorrentes da constatação de que, passados dez anos da publicação, houve um direcionamento dos artigos para discutirem a importância da GSCM e poucas publicações sobre análise do ciclo de vida e design verde. Nesse caso, as publicações analisadas que abordaram a categoria importância da GSCM trataram principalmente de práticas (DIABAT; GOVINDAN, 2011; ZHU; SARKIS, 2006; GOVINDAN et al., 2014) e de inovações em GSCM (WOOI; ZAILANI, 2010; ELTAYEB; ZAILANI; RAMAYAH, 2011).

Em práticas de GSCM os temas mais recorrentes foram gestão dos fornecedores (ZHU; SARKIS; LAI, 2012), dos clientes (ZHU; GENG; SARKIS, 2016), gestão de resíduos (MAHMOOD et al., 2013), compras verdes (THUN; MULLER, 2010), recuperação do investimento (RHA, 2015), gestão ambiental interna (RHA, 2015) e requisitos legais (HOLT; GHOBADIAN, 2009). Como consequência têm-se a necessidade de alterar as categorias do modelo e inserir uma estrutura que contemple práticas de GSCM para tratar destas e outras práticas que o campo amadurecerá. $\mathrm{A}$ inserção de um tópico que trate especificamente sobre práticas de GSCM (ZHU et al., 2008) justifica-se em função do número de publicações que abordam tais temas. A figura 7, a seguir, apresenta esta proposta de estrutura.

Já a produção científica sobre o tema inovações ambientais demonstrará o nível de maturidade da consciência ambiental consolidado nas organizações. Isso acontecerá por meio da evolução das práticas de GSCM e, portanto, responderá como evoluem e se relacionam tais práticas. O nível de maturidade do sistema de 
gestão ambiental será diretamente proporcional a consolidação dessas práticas de GSCM no âmbito organizacional.

Ainda sobre a produção científica da categoria importância da GSCM, ficou constatado que os principais assuntos correlatos, ao se tratar de práticas e de inovações, foram barreiras e condutores de implementação (SARKIS, 2006; CHEN et al., 2012 e TESTA; IRALDO, 2010), avaliação das práticas de GSCM (OLUGU; WONG, 2012; SARKIS; DOU; ZHU, 2013) e revisão de literatura (GOVINDAN et al. 2014; JABBOUR et al., 2014). Esta evidência aponta que ainda existe a necessidade de ampliar a discussão de como se deve lidar com as barreiras e potencializar condutores para a implementação da GSCM, demonstrando com isso, que o campo ainda não está consolidado em função das poucas publicações paradigmáticas.

Portanto, é necessário dividir as publicações que tratam de barreiras e condutores para a implantação, revisão de literatura e estudos bibliométricos inserindo uma categoria que discutas as teorias aplicadas ao campo. A inserção dessas três fontes de análise possibilitará uma melhor compreensão do tema e um direcionamento para pesquisas futuras. A figura 7, a seguir, demonstra essas evidências por meio de uma estrutura conceitual.

Analisando a categoria práticas de operações verde, ficou evidenciado que os estudos focaram em práticas de manufatura e remanufatura verde (DESHENG-WU; OLSON; BIRGE, 2013; KANNAN; JABBOUR; JABBOUR, 2014), logística reversa (SRIVASTAVA, 2008; DE LA FUENTE; ROS; CARDÓS, 2008) e gestão de resíduos na área pública (CONTRERAS et al., 2008; CUCCHIELLA; D'ADAMO, 2014; CANIATO et al., 2014; GENG; ZHU; HAIGHT, 2007; ZANGHELINI et al., 2014). Constata-se, portanto, a necessidade de mais estudos que tratem de práticas de gestão de resíduos em organizações privadas, cumprimento de requisitos legais, relacionamento com fornecedores, comprometimento da gestão, cooperação com clientes, tecnologia da informação aplicada à GSCM, compras verdes e recuperação de investimentos.

Logo, percebe-se que a categoria de operações verde pode abarcar uma categoria de práticas de GSCM inserindo uma temática que começa a despontar em estudos recentes, ou seja, a tecnologia da informação aplicada a integração das operações, ao desenvolvimento e análise do ciclo de vida do produto. 
Finalmente, sobre ecodesign, incorpora-se a categoria de práticas de GSCM para direcionar os estudos sobre análise do ciclo de vida, pesquisa e desenvolvimento e projeto verde. O objetivo é possibilitar a integração com tecnologia da informação para que a arquitetura de um produto ambientalmente amigável possibilite, por exemplo o rastreamento, a desmontagem, a recuperação entre outras atividades. A figura 7 deste estudo apresenta essa reestruturação do quadro original de Srivastava (2007).

Assim, apesar de existir uma produção bastante diversificada sobre o tema, principalmente sobre a importância da GSCM, há muitas pesquisas embrionárias sobre práticas de GSCM (SELLITO et al., 2013; BARBIERI et al., 2014). Observa-se uma tendência desses estudos se concentrarem em atividades emergentes para a conversão de processos tanto a montante (upstream - nas relações com clientes e pesquisa e desenvolvimento), como a jusante (downstream - referindo-se às relações da empresa com os fornecedores e partes interessadas) e, com isso, integrar toda a cadeia de suprimentos.

Da mesma forma, essa produção científica aponta uma necessidade de mirar-se também em estudos sobre a integração de pesquisas e desenvolvimentos com a tecnologia da informação, a fim de potencializar inovações na cadeia de suprimentos.

Figura 7- Contexto do Problema atualizado

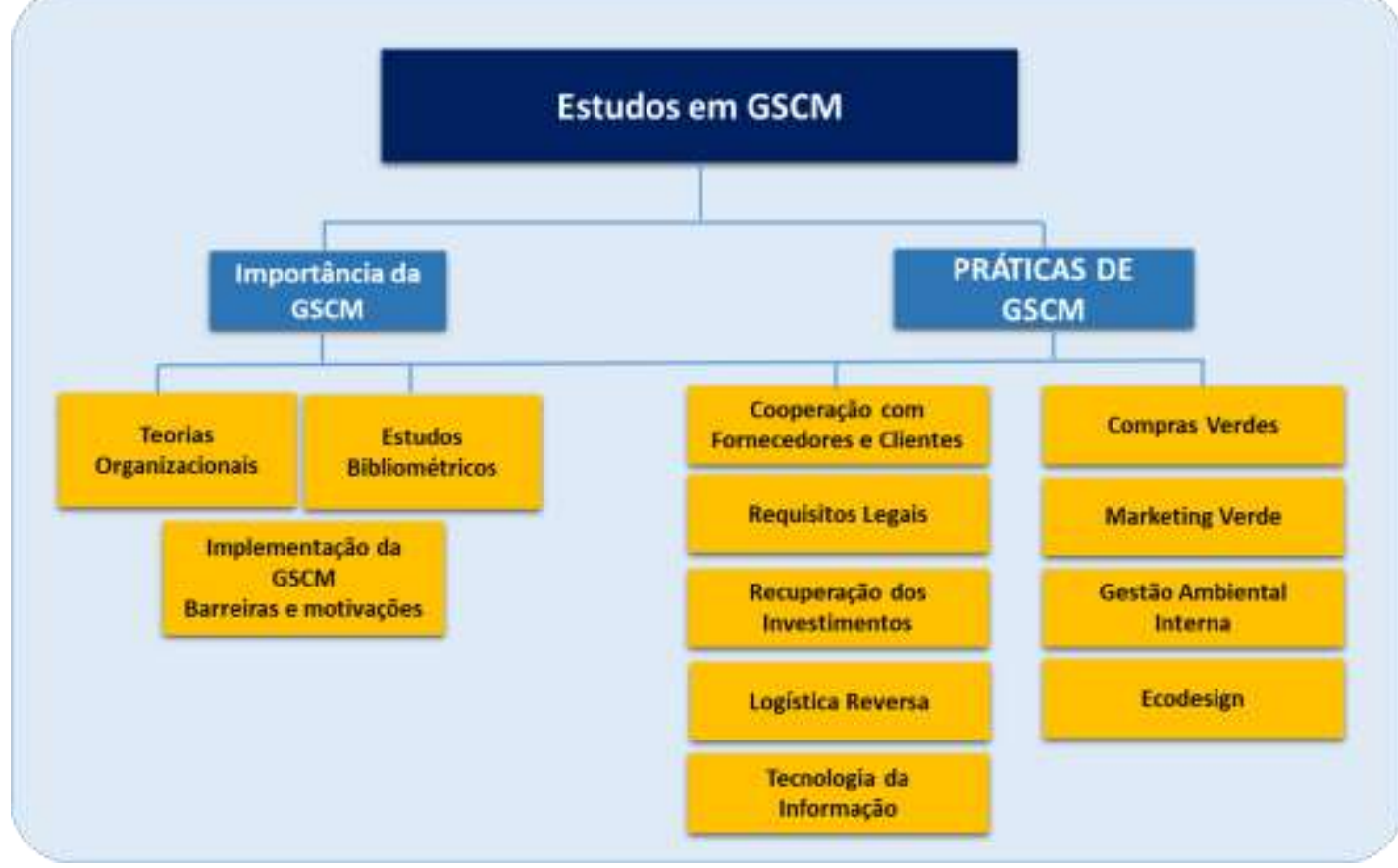

Fonte: Elaborado pelos autores (2018) 
O tema proposto para este estudo indica uma lacuna a ser explorada e, com isso, direciona algumas interessantes linhas para futuras investigações em GSCM. Em particular, existe a necessidade de se ampliar o debate sobre estudos que integrem a cadeia de suprimentos, tanto a montante como a jusante, adotando um sistema holístico de abordagem para a inovação em GSCM e com isso responder à questão de como integrar um modelo de planejamento estratégico orientado ambientalmente com os modelos operacionais de práticas de GSCM e com isso gerar vantagem competitiva por meio de inovações ambientais.

\section{CONCLUSÕES}

O objetivo de apresentar uma visão ampla e integrada do estado da arte do tema GSCM, a partir de Srivastava (2007), foi alcançado. No artigo publicado por Srivastava em 2007, o autor apresentou, para um período de pesquisa de 16 anos (1989 a 2005), 227 artigos publicados com foco em gestão de operações e GSCM. No caso deste estudo, para um período de 11 anos, já se constatam, somente na base utilizada, 456 artigos publicados com ênfase em discutir a importância da GSCM e práticas de GSCM.

Sobre o objetivo de se resgatar o estado da arte do tema GSCM a partir de 2006 destaca-se a materialização de uma base de artigos publicados onde foram identificados os principais autores e um perfil de utilização das palavras chaves mais utilizadas o que poderá auxiliar as futuras pesquisas.

Outro ponto a destacar é sobre a categorização proposta pelo autor. Nesse caso, ficou evidenciado que a grande maioria dos estudos publicados ainda transita pela categoria importância da GSCM, indicando que há ainda a necessidade de se estruturar um nível de temática a ser abordada quando se tratar dessa categoria, o que foi sugerido conforme figura 7 deste estudo.

O estudo também apontou que, na base pesquisada, existem poucas pesquisas sobre a categoria ecodesign, indicando também um campo fértil de novas pesquisas. Na categoria operações verdes, ficou constatado um número maior de pesquisas sobre manufatura e remanufatura. Como sugestão foi apresentado a inserção de uma categoria que incorpore de forma estruturada as práticas de GSCM independente de as mesmas estarem no âmbito das operações verde ou ecodesign. 
Também, ficou evidenciada uma limitação deste estudo que não conseguiu ampliar a análise para o nível 3 de Srivastava (2007) e com isso identificar se tais pesquisas tendiam para atividades práticas como redução, reciclagem, remanufatura, gestão de estoques, planejamento e programação da produção, reuso ou recuperação de produtos.

Normalmente, quando os termos meio ambiente e práticas ambientais entram em cena, a maioria dos gerentes de operação e as partes interessadas identificam uma restrição relativa à geração de custos. Portanto, é necessária integração do tema com práticas de inovações que representem a geração de valor por meio de processos ambientalmente amigáveis. Assim, este estudo acaba por desafiar a comunidade acadêmica a compreender as restrições e condutores que levam os gestores e as partes interessadas a tornarem a gestão da cadeia de suprimentos mais verde.

\section{REFERÊNCIAS}

AJAMIEH, A.; BENITEZ, J.; BRAOJOS, J.; GELHARD, C. IT infrastructure and competitive aggressiveness in explaining and predicting performance. Journal of Business Research. v.69, n.10, p. 4667-4674, 2016. DOI: https://doi.org/10.1016/j.jbusres.2016.03.056

AYRES, R.U; FERRER, G.; LEYNSEELE T. V. Eco-efficiency, asset recovery and remanufacturing. European Management Journal. v.15, p. 557-574, 1997. DOI: https://doi.org/10.1016/S0263-2373(97)00035-2

BAI, C.; SARKIS, J. Integrating sustainability into supplier selection with grey system and rough set methodologies. International Journal of Production Economics. v.124, n.1, p. 252-264, 2010. DOI: https://doi.org/10.1016/.i.ipe.2009.11.023

BAI, C. SARKIS, J.; WEI, X. Evaluating ecological sustainable performance measures for supply chain management. Supply Chain Management: An International Journal. v.17 n.1, p.78-92, 2012. DOI: https://doi.org/10.1108/13598541211212221

BARBIERI, J. C.; SOUSA FILHO, J. M.; BRANDÃO C. N.; DI SERIO, L. C.; REYES JUNIOR, E. Gestão Verde da Cadeia de Suprimentos: análise da produção acadêmica brasileira.

Produção online, v.14, n.3, p.1104-1128, 2014.

BOJARSKI, A. D.; LAÍNEZ, J. M.; ESPUÑA, A.; PUIGJANER, L. Incorporating environmental impacts and regulations in a holistic supply chains modeling: An LCA approach. Computers \& Chemical Engineering, v.33, n.10, p. 1747-1759, 2009. DOI:

https://doi.org/10.1016/j.compchemeng.2009.04.009

CANIATO, F.; CARIDI, M.; CRIPPA, L.; MORETTO, A. Using social network and stakeholder analysis to help evaluate infectious waste management: A step towards a holistic 
assessment. Waste Management, v.34, n.5, p. 938-951, 2014. DOI:

https://doi.org/10.1016/j.wasman.2014.02.011

CARVALHO, H.; GOVINDAN, K.; AZEVEDO, S. G.; CRUZ-MACHADO, V. Green supply chain design: A mathematical modeling approach based on a multi-objective optimization model. International Journal of Production Economics. v.183 (B), p. 421-432, 2017.

CHOUINARD, M.; D'AMOURS, S.; AÏT-KADI, D. Integration of reverse logistics activities within a supply chain information system. Computers in Industry. v.56, p.105-124, 2005. DOI: https://doi.org/10.1016/..compind.2004.07.005

CHEN, C. The application of interpretive structural modeling method to develop verity design solution of case host preference-based products: A case study of Razor. Journal of Theoretical and Applied Information Technology, v.35, n.1, 92-99, 2012.

CHIOU, T.; CHAN, H.; LETTICE, F.; CHUNG, S. The Influence of Greening the Suppliers and Green Innovation on Environmental Performance and Competitive Advantage in Taiwan. Transportation Research. Part E, v.47, p.822-836, 2011. DOI: https://doi.org/10.1016/..tre.2011.05.016

CONTRERAS, F.; HANAKI, K.; ARAMAKI, T.; CONNORS, S. Application of analytical hierarchy process to analyze stakeholders preferences for municipal solid waste management plans, Boston, USA. Resources, Conservation and Recycling. v.52, n.7, p.979-991, 2008. DOI: https://doi.org/10.1016/j.resconrec.2008.03.003

COOK, D. J; MULROW, C. D.; HAYNES, R.B. Systematic reviews: synthesis of best evidence for clinical decisions. Annals of Internal Medicine.v.126, n.5, p.376-380, 1997.DOI: https://doi.org/10.7326/0003-4819-126-5-199703010-00006

COOPER, H. Synthesizing Research. Thousand Oaks: Sage, 1988.

CUCCHIELLA, F.; D'ADAMO; GASTALDI. Implementation of a real option in a sustainable supply chain: An empirical study of alkaline battery recycling. International Journal of Systems Science. v.45, n.6, p.1268-1282, 2014. DOI: https://doi.org/10.1080/00207721.2012.761458

DE LA FUENTE, M. V; ROS, L.; CARDÓS, M. Integrating Forward and Reverse Supply Chains: Application to a metal-mechanic company. International Journal of Production Economics, v.111, n.2, p.782-792, 2015. ISSN 0925-5273. Recuperado em 08.03.2015 de: <http://www.sciencedirect.com/science/article/pii/S0925527307001648.

DESHENG-WU, D. L. OLSON, D.; BIRGE J. R. Risk management in cleaner production. Journal of Cleaner Production. v.53, p.1-6, 2013. DOI:

https://doi.org/10.1016/j.jclepro.2013.02.014

DIABAT, A.; GOVINDAN, K. An Analysis of the Drivers Affecting the Implementation of Green Supply Chain Management. Resources, Conservation and Recycling. p.659-667, 2011. DOI: https://doi.org/10.1016/j.resconrec.2010.12.002

ELTAYEB, T. K; ZAILANI, S.; RAMAYAH, T. Green supply chain initiatives among certified companies in Malaysia and environmental sustainability: Investigating the outcomes.

Resources, Conservation and Recycling, v.55, n.5, p.495-506, 3// 2011. ISSN 0921-3449.

Recuperado em 08.03.2015 de: <

http://www.sciencedirect.com/science/article/pii/S0921344910002041. 
ELLRAM, L. M; TATE, W.; CARTER, C. R. Applying 3DCE to environmentally responsible manufacturing practices. Journal of Cleaner Production, v.16, n.15, p.1620-1631, 2008. DOI: https://doi.org/10.1016/j.jclepro.2008.04.017

FAHIMNIA, B.; SARKIS, J.; ESHRAGH, A. A Tradeoff Model for Greesn Supply Chain Planning: A Leanness-versus-Greenness Analysis. Omega, 2015. DOI: https://doi.org/10.1016/j.omega.2015.01.014

FERRER, G.; WHYBARK, D. C. Material planning for a remanufacturing facility. Production and Operations Management. v.10, p.112-124, 2001. DOI: https://doi.org/10.1111/j.1937$\underline{5956.2001 . t b 00073 . x}$

FLEISCHMANN, M., BEULLENS, P., BLOEMHOF-RUWAARD, J. M. \& VAN WASSENHOVE, L. N. The impact of product recovery on logistics network design. Production \& Operations Management. v.10, p.156-173, 2001. DOI: https://doi.org/10.1111/j.1937-5956.2001.tb00076.x

FIGUEIRA, A. A.; BURI, M. R. Os benefícios da utilização do Sistema Warehouse Management System na cadeia de logística reversa no Brasil. Exacta - EP, São Paulo, v.15, n.2, p.245-257, 2017.

FORTES, J. Green Supply Chain Management: A Literature Review, Otago Management Graduate Review. v.7, p.51-62, 2009.

GANGA, G. M. D.; RODRIGUES, L. R.; YOSHINO, R. T.; SANTA-EULALIA, L. A. Métodos quantitativos para seleção de fornecedores sustentáveis: uma revisão sistemática da literatura. v.16, n.4, p.1434-1457, 2016.

GLANTSCHNIG, W. J. Green design: an introduction to issues and challenges. IEEE Transactions on Components. Packaging and Manufacturing Technology-Part A, p.508513, 1994. DOI: https://doi.org/10.1109/95.335033

GATENBY, D. A.; FOO, G. Design for X (DFX): key to competitive, profitable products. AT\&T Technical Journal. v.69, p.2-15, 1990. DOI: https://doi.org/10.1002//.15387305.1990.tb00332.x

GENG, Y; ZHU, Q. \& HAIGHT, M. Planning for integrated solid waste management at the industrial Park level: A case of Tianjin, China. Waste Management. v.27, n.1, p.141-150, 2007. DOI: https://doi.org/10.1016/j.wasman.2006.07.013

GOVINDAN, K.; KALIYAN, M.; KANNAN, D.; HAQ, A. N. Barriers analysis for green supply chain management implementation in Indian industries using analytic hierarchy process. International Journal of Production Economics. v.147(B), p.555-568, 2014.

GOVINDAN, K.; SARKIS, J.; JABBOUR, C. J. C.; ZHU, Q.; GENG, Y. Eco-efficiency based green supply chain management: Current status and opportunities. European Journal of Operational Research. v.233, n.2, p.293-298, 2014. DOI:

https://doi.org/10.1016/j.ejor.2013.10.058

GOVINDAN, K. JABBOUR, A. B.; JABBOUR, J. C. Selecting green suppliers based on GSCM practices: Using fuzzy TOPSIS applied to a Brazilian electronics company. European Journal of Operational Research. v.233, p.432-447, 2014. DOI:

https://doi.org/10.1016/..ejor.2013.07.023 
GUIDE, V. D. R.; SRIVASTAVA, R. Inventory buffers in recoverable manufacturing. Journal of Operations Management. v.16, p.551-568, 2007. DOI: https://doi.org/10.1016/S02726963(97)00024-7

HOLT, D. Managing The Interface Between Suppliers and Organizations for Environmental Responsibility - an exploration of current practices in the Uk. Corporate Social

Responsibility and Environmental Management. 2004. DOI: https://doi.org/10.1002/csr.55

HOLT, D.; GHOBADIAN, A. An Empirical Study of Green Supply Chain Management Practices. Amongst UK Manufacturers. Journal of Manufacturing Technology

Management. v.20, n.7, p.933-966, 2009. DOI: https://doi.org/10.1108/17410380910984212

HSU, C.W.; KUO, T-C.; CHEN, S-H.; HU, A. H. Using DEMATEL to develop a carbon management model of supplier selection in green supply chain management. Journal of Cleaner Production. v.56, n.0, p.164-172, 2013. DOI:

https://doi.org/10.1016/j.jclepro.2011.09.012

JABBOUR, A. B. L. S.; JABBOUR, C. J. C. Are supplier selection criteria going green? Case studies of companies in Brazil. Industrial Management \& Data Systems. v.109, n.4, p.477495, 2009. DOI: https://doi.org/10.1108/02635570910948623

JABBOUR, A. B. L. S.; JABBOUR, C. J. C.; LATAN, H.; TEIXEIRA, A. A. \& DE OLIVEIRA, J. $\mathrm{H}$. C. Quality management, environmental management maturity, green supply chain practices and green performance of Brazilian companies with ISO 14001 certification: Direct and indirect effects. Transportation Research Part E: Logistics and Transportation Review. v.67, n.0, p.39-51, 2014. DOI: https://doi.org/10.1016/..tre.2014.03.005

KANNAN, D.; DE SOUSA JABBOUR, A. B. L.; JABBOUR, C. J. C. Selecting green suppliers based on GSCM practices: Using fuzzy TOPSIS applied to a Brazilian electronics company. European Journal of Operational Research. v.233, Issue 2, p.432-447, 2014. DOI: https://doi.org/10.1016/i.ejor.2013.07.023

KELLE, P.; SILVER, E. A. Forecasting the returns of reusable containers. Journal of Operations Management. v.8, 17-35, 1989. DOI: https://doi.org/10.1016/S0272$\underline{6963(89) 80003-8}$

KITCHENHAM, B. Procedures for Performing Systematic Reviews. Joint Technical Report, TR/SE-0401 and NICTA 0400011T.1, Keele University, 2004. Recuperado em 18.04.2015 de:

http://www.idi.ntnu.no/emner/empse/papers/kitchenham_2004.pdf.

KOPICKI, R. J.; LEGG, L.; BERG, L. M. J.; DASAPPA, V.; MAGGIONI, C. Reuse and Recycling: Reverse Logistics Opportunities. Oak Brook, IL: Council of Logistics Management, 1993.

LENOX, M.; KING, A.; EHRENFELD, J. An assessment of design-for-environment practices in leading US electronic firms. Interfaces. v.30, p.83-94, 2000. DOI:

https://doi.org/10.1287/inte.30.3.83.11669

LINTON, J.; KLASSEN, R.; JAYARAMAN, V. Sustainable supply chains: An introduction. Journal of Operations Management. v.25, n.6, p.1075-1082, 2007. ISSN 02726963. 
MAHMOOD, W. H.; AB RAHMAN, M. N.; MD DEROS, B.; JUSOFF, K.; SAPTARI, A.; EBRAHIM, Z.; MOHAMED SULTAN, A. A.; ABU BAKAR, M. H.; SUBRAMONIAN, S.; JANO, Z. Manufacturing performance in green supply chain management. World Applied Sciences Journal. v.21(SPECIAL ISSUE2), p.76-84, 2013.

MEHMET A. I. Green Supply Chain Management: Product Life Cycle Approach. Journal of Cleaner Production. v.56, p.199-213, 2013. DOI: https://doi.org/10.1016/i.jclepro.2011.12.004

MUKHOPADHYAY, S.K.; SETOPUTRO, R. Optimal return policy and modular design for build-to-order products. Journal of Operations Management. v.23, p.496-506, 2005. DOI: https://doi.org/10.1016/j.jom.2004.10.012

NADRUZ, V. N.; GALLARDO, A. L. C. F.; RUIZ, M. S.; RAMOS, H. R. et al. Avaliação de desempenho ambiental a partir das práticas de gestão ambiental para qualificação da contratação de obras de linhas de transmissão. Exacta - EP, São Paulo, v.15, n.2, p.187202, 2017.

NAVIN-CHANDRA, D. Design for environmentability. Design Theory and Methodology. v.31, p.99-124, 1991.

OLUGU, E. U.; WONG, K. Y. An expert fuzzy rule-based system for closed-loop supply chain performance assessment in the automotive industry. Expert Systems with Applications. v.39, n.1, p.375-384, 2012. DOI: https://doi.org/10.1016/j.eswa.2011.07.026

SARKIS, J. Greening the Supply Chain. Springer Science Business Media New York, Clark University. EUA, 2006.

SARKIS, J. A Boundaries and Flows Perspective of Green Supply Chain Management. Working paper n. 2009-07, 2009.

SARKIS, J.; ZHU, Q.; LAI, K. H. An organizational theoretic review of green supply chain management literature. International Journal of Production Economics. v.130, n.1, p.115, 2011.

SARKIS, J.; DOU, Y; ZHU, Q. SARKIS, J. D., Y.; ZHU, Q. Integrating strategic carbon management into formal evaluation of environmental supplier development programs, 2013. DOI:

https://doi.org/10.1016/j.ijpe.2010.11.010

SELLITTO, M. A.; BORCHARDT, M.; PEREIRA, G. M.; PACHECO, D. A. J. Gestão de Cadeias de Suprimentos Verdes: quadro de trabalho. Revista Produção Online, v.13, n. 1, p. 351-374, jan./mar, 2013. DOI: https://doi.org/10.14488/1676-1901.v13i1.1181

SINGHAL, P. Green Supply Chain and eco-design in electronic industry. Delhi Business Review. v.14, n.1, jan-jul, 2013.

SHANG, K.; LU, C.; LI, S. A taxonomy of green supply chain management capability among electronics-related manufacturing firms in Taiwan. Journal of Environmental Management, v.91, n.5, p.218-1226, 2010. DOI: https://doi.org/10.1016/.j.jenvman.2010.01.016

SHI, V. G.; KOH. S. C. L.; BALDWIN, J.; CUCCHIELLA, F. Natural resource based green supply chain management. Supply Chain Management. v.17, n.1, p.54-67, 2012.

Recuperado em 08.03.2015, de: <http://www.scopus.com/inward/record.url?eid=2-s2.084856786783\&partnerlD $=40 \&$ md5 $=d 91$ dabf73a22a0ff4e82cdb48bbba6f1 $>$. 
SRIVASTAVA, S. K. Green supply-chain management: A state-of-the-art literature review. International Journal of Management Reviews. v.9, n.1, p.53-80, 2007. DOI: https://doi.org/10.1111/j.1468-2370.2007.00202.x

SRIVASTAVA, S. K. Network design for reverse logistics. Omega. v.36, n.4, p.535-548. DOI: https://doi.org/10.1016/j.omega.2006.11.012

TESTA, F.; IRALDO, F. Shadows and lights of GSCM (Green Supply Chain Management): determinants and effects of these practices based on a multi-national study. Journal of Cleaner Production. v.18, n.10-11, 953-962, 2015. ISSN 0959-6526. Recuperado em 16.03.2015 de: < http://www.sciencedirect.com/science/article/pii/S0959652610001058.

TRANFIELD, D.; DENYER, D. A methodology for developing evidence-informed management knowledge by means of systematic review. British Journal of Management.v.14, n.3, p.207-223, 2003. DOI: https://doi.org/10.1111/1467-8551.00375

TRITOS L.; KEAH-CHOON T.; DOTUN A. Green Supply Chain Management Practices and Performance. Asia Pacific Industrial Engineering and Management System, 2013. DOI: https://doi.org/10.1016/j.jclepro.2012.07.015

TSENG, M.; CHIU, S. F.; TAN, R. R.; SIRIBAN-MANALANG, A. B. Sustainable consumption and production for Asia: sustainability through green design and practice. Journal of Cleaner Production. v.40, p.1-5.

VACHON, S. Green supply chain practices and the selection of environmental technologies. International Journal of Production Research. v.45, n.18/19, p.4357-79, 2005. DOI:

VACHON, S.; KLASSEN, R. D. Environmental management and manufacturing performance: The role of collaboration in the supply chain. International Journal of Production Economics. v.111, n.2, p.299-315, 2008. DOI:

https://doi.org/10.1016/j.ijpe.2006.11.030

VAN HOEK, R. I. From reversed logistics to green supply chains. Supply Chain Management. v.4, p.129-135, 1999. DOI: https://doi.org/10.1108/13598549910279576

ZANGHELINI, G. M.; CHERUBINI, E.; ORSI, P.; SOARES, S. R. Waste management Life Cycle Assessment: the case of a reciprocating air compressor in Brazil. Journal of Cleaner Production. v.70, p.164-174, 2014. DOI: https://doi.org/10.1016/j.jclepro.2014.02.034

ZHU Q.; SARKIS J. An inter-sectoral comparison of green supply chain management in China: drivers and practices. Journal of Cleaner Production.v.14, n.5, p.472-486, 2006. DOI: https://doi.org/10.1016/j.jclepro.2005.01.003

ZHU, Q., SARKIS, J.; LAI, K. Confirmation of a measurement model for green supply chain management practices implementation. International Journal of Production Economics. v.111, n.2, p.261-273, 2008. DOI: https://doi.org/10.1016/j.ijpe.2006.11.029

ZHU, Q.; SARKIS, J.; LAI, K. Examining the effects of green supply chain management practices and their mediations on performance improvements. International Journal of Production Research v.50, n.5, p.1377-1394, 2012a. DOI:

https://doi.org/10.1080/00207543.2011.571937 
ZHU, Q.; SARKIS, J.; LAI, K. Green supply chain management innovation diffusion and its relationship to organizational improvement: an ecological modernization perspective.

Journal of Engineering and Technology Management. v.29, p.168-185, 2012b. DOI: https://doi.org/10.1016/j.jengtecman.2011.09.012

ZHU, Q.; SARKIS, J.; CORDEIRO, J. J.; LAI, K. Firm-level correlates of emergent green supply chain management practices in the Chinese context. Omega. v.36, n.4, p.577-591. DOI: https://doi.org/10.1016/j.omega.2006.11.009

ZHU, Q., GENG, Y.; SARKIS, J. Shifting Chinese organizational responses to evolving greening pressures. Ecological Economics v.121, p.65-74, 2016.DOI:

https://doi.org/10.1016/j.ecolecon.2015.11.010

WANG, F; LAI, X.; SHI, N. A multi-objective optimization for green supply chain network design. Decision Support Systems. v.51, n.2, p.262-269, 2011. DOI:

https://doi.org/10.1016/j.dss.2010.11.020

WOOI, G. C.; ZAILANI, S. Green supply chain initiatives: Investigating on the barriers in the context of SMEs in Malaysia. International Business Management. v.4, n.1, 20-27, 2010. DOI: https://doi.org/10.3923/ibm.2010.20.27

YARAHMADI, M; HIGGINS, P. G.; CLEMENTS, M. Greening supply chains: compliance and monitoring-oriented practices vs. cooperative-oriented practices. IADIS International

Conference on Sustainability, Technology and Education, 2012.

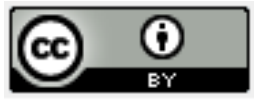

Artigo recebido em: 05/06/2018 e aceito para publicação em: 06/11/2018 DOI: http://dx.doi.org/10.14488/1676-1901.v18i4.3271 